Article

\title{
Macromolecular Architectures Designed by Living Radical Polymerization with Organic Catalysts
}

Miho Tanishima ${ }^{1}$, Atsushi Goto ${ }^{1, *}$, Lin Lei ${ }^{1}$, Akimichi Ohtsuki ${ }^{1}$, Hironori Kaji ${ }^{1}$, Akihiro Nomura ${ }^{1,2}$, Yoshinobu Tsujii ${ }^{1,3}$, Yu Yamaguchi ${ }^{4}$, Hiroto Komatsu ${ }^{4}$ and Michihiko Miyamoto ${ }^{4}$

1 Institute for Chemical Research, Kyoto University, Uji, Kyoto 611-0011, Japan;

E-Mails: tanishima.miho.83s@st.kyoto-u.ac.jp (M.T.); lei.lin.8m@kyoto-u.ac.jp (L.L.); ohtsuki.akimichi.2c@kyoto-u.ac.jp (A.O.); kaji@scl.kyoto-u.ac.jp (H.K.); akihiro.nomura@chbe.gatech.edu (A.N.); tsujii@scl.kyoto-u.ac.jp (Y.T.)

2 School of Chemical \& Biomolecular Engineering, Georgia Institute of Technology, 311 Ferst Dr., Atlanta, GA 30332-0100, USA

3 Japan Science and Technology Agency, Core Research for Evolutionary Science and Technology (JST, CREST), Uji, Kyoto 611-0011, Japan

4 Techno Research Center, Godo Shigen Sangyo Co., Ltd., 1365 Nanaido, Chosei-Mura, Chosei-Gun, Chiba 299-4333, Japan; E-Mails: y.yamaguchi@godoshigen.co.jp (Y.Y.); h.komatsu@godoshigen.co.jp (H.K.); m.miyamoto@godoshigen.co.jp (M.M.)

* Author to whom correspondence should be addressed; E-Mail: agoto@scl.kyoto-u.ac.jp; Tel.: +81-774-38-3151; Fax: +81-774-38-3148.

Received: 27 December 2013 / Accepted: 22 January 2014 / Published: 27 January 2014

\begin{abstract}
Well-defined diblock and triblock copolymers, star polymers, and concentrated polymer brushes on solid surfaces were prepared using living radical polymerization with organic catalysts. Polymerizations of methyl methacrylate, butyl acrylate, and selected functional methacrylates were performed with a monofunctional initiator, a difunctional initiator, a trifunctional initiator, and a surface-immobilized initiator.
\end{abstract}

Keywords: living radical polymerization; organic catalysts; block copolymers; triblock copolymers; star polymers; polymer brushes 


\section{Introduction}

Living radical polymerization (LRP) has attracted increased attention as it allows for the rational design of polymer architectures with predictable molecular weights and narrow molecular weight distributions [1-3]. LRP can offer, not only well-defined linear homopolymers, but also diblock copolymers, triblock copolymers, star polymers, and surface-grated brush polymers with sophisticated structures, which have many useful applications.

LRP is based on the reversible activation of a dormant species (Polymer-X) to a propagating radical (Polymer•) (Scheme 1a). A sufficiently large number of activation-deactivation cycles are required for low polydispersity [4-7]. Examples of the capping agent $(\mathrm{X})$ include nitroxides, dithioesters, tellurides, and halogens [8-15]. Halogens are combined with transition metal catalysts [13-15].

We recently developed new LRP systems using iodine as a capping agent and organic molecules as catalysts. We developed two mechanistically different systems referred to as reversible chain transfer catalyzed polymerization (RTCP) [16-23] and reversible coordination mediated polymerization (RCMP) [24-27].

RTCP uses a reversible chain transfer of Polymer-I with a catalyst radical to generate Polymer• and a catalyst (deactivator) (Scheme 1b). RTCP consists of a dormant species, a catalyst (deactivator), and a radical source that supplies Polymer. The catalysts include germanium, phosphorus, nitrogen, oxygen, and carbon-centered iodides including $N$-iodosuccinimide (NIS) (Figure 1) [17] used in the present work.

RCMP utilizes a reversible coordination of Polymer-I with a catalyst (activator) to generate Polymer• and a catalyst-iodine complex. RCMP consists of a dormant species and a catalyst (activator). The catalysts include amines and organic salts such as tetrabutylammonium iodide (BNI) (Figure 1) [27] and methyltributylphosphonium iodide (BMPI) (Figure 1) [27] used in the present work.

The attractive features of RTCP and RCMP include no use of special capping agents or metals. The catalysts are inexpensive, relatively non-toxic, easy to handle, and amenable to a wide range of monomers including styrenes, methacrylates, acrylates, acrylonitrile, and those with various functional groups. RTCP and RCMP can be facile and pervasive methodologies for various applications.

Scheme 1. Reversible activation: (a) General scheme; (b) RTCP; and (c) RCMP.

(a) Reversible activation (general scheme)

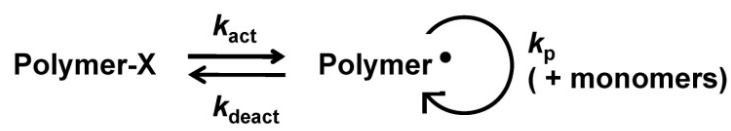

(b) RTCP

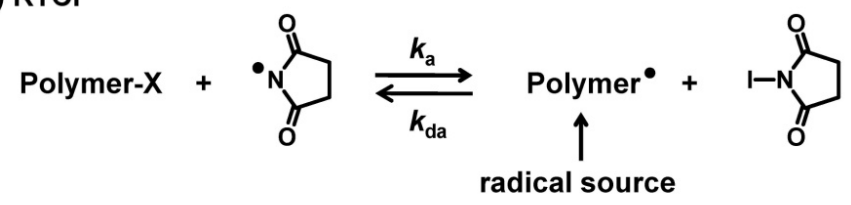

(c) RCMP

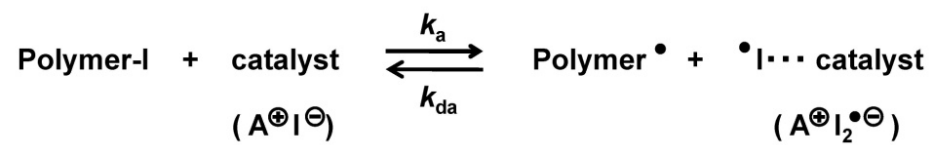


We previously reported the use of RTCP and RCMP in preparing well-defined linear polymers including homopolymers, random copolymers, and diblock copolymers [16-27]. In this paper, we report new examples of diblock copolymers and summarize the diblock copolymers prepared in previous and current works. We also report the syntheses of triblock copolymers, 3-arm star polymers, and surface-grafted brush polymers. Macromolecular designs of diblock, triblock, star, and brush architectures are important to widen the range of RTCP and RCMP applications. The structures and abbreviations of the studied monomers, catalysts, and initiating alkyl iodides (dormant species) are provided in Figure 1.

Figure 1. Structures and abbreviations of studied alkyl iodides (initiators), catalysts, and monomers.

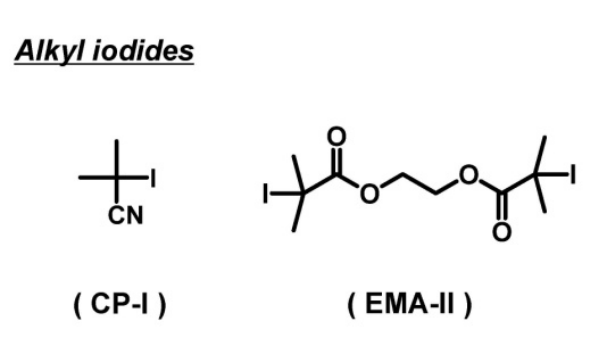

RTCP catalysts<smiles>O=C1CCC(=O)N1I</smiles>

( NIS )

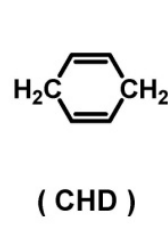

( CHD )
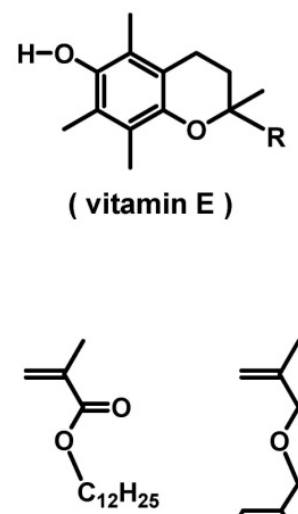

( LMA )

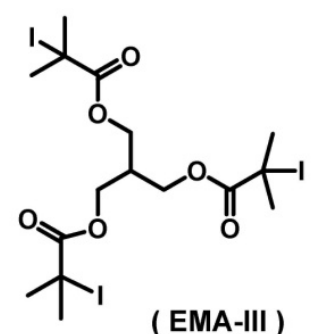

$\underline{\text { RCMP catalysts }}$

\section{Monomers}<smiles>C=CC(=O)OCCCC</smiles>

(BA)<smiles>C=C(C)C(=O)OC</smiles>

( MMA )

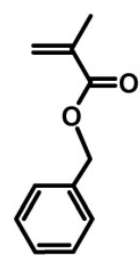

(BzMA)

$$
\mathrm{Bu}_{4} \mathrm{~N}^{\oplus} \Theta
$$

( BNI )<smiles>CCO[Si](C)(OCC)OCCCCC(C)(C)C(=O)O[Si](C)(CC)OC</smiles>

( IHE )

\section{Experimental Section}

\subsection{Materials}

Methyl methacrylate (MMA) (99\%, Nacalai Tesque, Kyoto, Japan), glycidyl methacrylate (GMA) (97\%, Aldrich, St. Louis, MI, USA), 2-(dimethylamino)ethyl methacrylate (DMAEMA) (99\%, Wako Pure Chemical, Osaka, Japan), methacrylic acid (MAA) (99\%, Nacalai), lauryl methacrylate (LMA) (Aldrich, 96\%), benzyl methacrylate (BzMA) (96\%, Aldrich), and butyl acrylate (BA) (99\%, Nacalai) were purified on an alumina column. 2-cyanopropyl iodide (CP-I) [99\%, Tokyo Chemical Industry (TCI), Tokyo, Japan (contract service)], I2 (98\%, Wako), NIS (98\%, Wako), 1,4-cyclohexiadiene (CHD) (98\%, TCI), vitamin E (99.5\%, Wako), BNI (98\%, TCI), BMPI (96\%, Wako), azobis(isobutyronitrile) (AIBN) (98\%, Wako), 2,2'-azobis(2,4-dimethyl valeronitrile) (V65) (95\%, Wako), 2,2'-azobis(4-methoxy-2,4-dimethyl valeronitrile) (V70) (95\%, Wako), sodium iodide (NaI) 
(99.5\%, Wako), 2-bromoisobutyryl bromide (98\%, TCI), ethylene glycol (99.5\%, Wako), glycerol (99\%, Wako), and pyridine (99.5\%, Kishida Chemical, Osaka, Japan) were used as received.

\subsection{GPC Measurements}

Gel permeation chromatography (GPC) analysis was performed on a Shodex GPC-101 liquid chromatograph (Tokyo, Japan) equipped with two Shodex KF-804L mixed gel columns $(300 \times 8.0 \mathrm{~mm}$; bead size $=7 \mu \mathrm{m}$; pore size $=20-200 \AA$ ). The eluent was tetrahydrofuran (THF) or dimethyl formamide (DMF) with a flow rate of $0.8 \mathrm{~mL} / \mathrm{min}\left(40^{\circ} \mathrm{C}\right)$. Sample detection and quantification were conducted using a Shodex differential refractometer RI-101 calibrated with known polymer concentrations in solvent. The monomer conversion was determined from the GPC peak area. The column system was calibrated using standard poly(methyl methacrylate)s (PMMAs). For the homopolymerizations of BA and LMA and the homopolymerization of MMA from a trifunctional initiator, the samples were also detected using a Wyatt Technology DAWN EOS multiangle laser light-scattering (MALLS) detector (Santa Barbara, CA, USA) equipped with a Ga-As laser $(\lambda=690 \mathrm{~nm})$. The refractive index increment $\mathrm{d} n / \mathrm{d} c$ was determined with a Wyatt Technology OPTILAB DSP differential refractometer $(\lambda=690 \mathrm{~nm})$.

\subsection{Preparation of Ethylene Glycol Bis(2-iodoisobutyrate) (EMA-II)}

Ethylene glycol (5.0 g: $80 \mathrm{mmol})$ and pyridine $(13.9 \mathrm{~g}: 176 \mathrm{mmol})$ were stirred in dichloromethane $(25 \mathrm{~mL})$. The mixture was slowly added to 2-bromoisobutyryl bromide (44.1 g: $192 \mathrm{mmol})$ in dichloromethane $15 \mathrm{~mL}$ and stirred for an hour. This white suspension was washed with aqueous $\mathrm{HBr}$ (5\%), saturated aqueous $\mathrm{Na}_{2} \mathrm{SO}_{3}$, and water and dried over $\mathrm{MgSO}_{4}$. Removal of the solvent under reduced pressure afforded the crude ethylene glycol bis(2-bromoisobutyrate) (EMA-BB), which was used in the subsequent reaction without further purification. ${ }^{1} \mathrm{H}$ NMR (400 $\mathrm{MHz}, \mathrm{CDCl}_{3}$ ): 1.92 (s, 12H, $\left.\mathrm{CCH}_{3}\right), 4.42$ (s, 4H, OCH $\left.\mathrm{CH}_{2} \mathrm{O}\right)$. EMA-BB (25.5 g: $\left.71 \mathrm{mmol}\right)$, and NaI (50.9 g: $\left.340 \mathrm{mmol}\right)$, were stirred in dry acetonitrile $(110 \mathrm{ml})$ at $80{ }^{\circ} \mathrm{C}$ for $8 \mathrm{~h}$. The reaction mixture was filtered off to remove $\mathrm{NaBr}$. The solution was concentrated under reduced pressure and diluted with dichloromethane. The mixture was washed with saturated aqueous $\mathrm{Na}_{2} \mathrm{SO}_{3}$ solution and dried over $\mathrm{MgSO}_{4}$. After removal of the solvent under reduced pressure, the residue was chromatographed on silica gel (ethyl acetate/hexane) to afford pure EMA-II in a $35 \%$ yield. $\left.{ }^{1} \mathrm{H} \mathrm{NMR} \mathrm{(400} \mathrm{MHz}, \mathrm{CDCl}_{3}\right)$ : $2.08\left(\mathrm{~s}, 12 \mathrm{H}, \mathrm{CCH}_{3}\right), 4.39$ (s, $\left.4 \mathrm{H}, \mathrm{OCH}_{2} \mathrm{CH}_{2} \mathrm{O}\right)$.

\subsection{Preparation of Glycerol Tris(2-iodoisobutyrate) (EMA-III)}

EMA-III was obtained from the same process as EMA-II. Glycerol was used instead of ethylene glycol to afford pure EMA-III in a 35\% yield. ${ }^{1} \mathrm{H}$ NMR $\left(400 \mathrm{MHz}, \mathrm{CDCl}_{3}\right): 2.08\left(\mathrm{~m}, 18 \mathrm{H}, \mathrm{CCH}_{3}\right)$, 4.33 (dd, 2H, ОСНHCHCHHO), 4.48 (dd, 2H, OCHНCHCHHO), and 5.37 (m, 1H, OCHНCHCHHO).

\subsection{Preparation of 6-(2-iodo-2-isobutyloxy)Hexyltriethoxysilane (IHE)}

6-(2-bromo-2-isobutyloxy)hexyltriethoxysilane (BHE) was prepared according to the literature [28]. BHE (6.2 g: $15 \mathrm{mmol})$ and $\mathrm{NaI}(11.23 \mathrm{~g}: 75 \mathrm{mmol})$ were stirred in dry acetone $(100 \mathrm{~mL})$ at $50{ }^{\circ} \mathrm{C}$ for 
two days, and the reaction mixture was evaporated to dryness. Dry chloroform (300 $\mathrm{mL})$ was subsequently added. The precipitated $\mathrm{NaI}$, which contained $\mathrm{NaBr}$, was filtered off. The solvent was evaporated, yielding IHE in a 98\% yield. ${ }^{1} \mathrm{H} \mathrm{NMR}\left(\mathrm{CDCl}_{3}\right): 0.64\left(\mathrm{t}, 2 \mathrm{H}, \mathrm{CH}_{2} \mathrm{Si}\right), 1.23(\mathrm{t}, 9 \mathrm{H}$, $\mathrm{CH}_{3} \mathrm{CH}_{2} \mathrm{OSi}$ ), 1.32-1.54 and 1.60-1.75 (broad, $8 \mathrm{H}, \mathrm{CH}_{2}$ ), 2.08 (s, 6H, $\mathrm{CCH}_{3}$ ), 3.81 (q, 6H, $\mathrm{SiOCH}_{2} \mathrm{CH}_{3}$ ), and $4.15\left(\mathrm{t}, J=6.8 \mathrm{~Hz}, 2 \mathrm{H}, \mathrm{OCH}_{2}\right)$.

\subsection{Polymerization}

In a typical run, a Schlenk flask containing a mixture of MMA (3 mL), CP-I, and a catalyst was heated at $60{ }^{\circ} \mathrm{C}$ under an argon atmosphere with magnetic stirring. For block copolymerization, the second monomer was subsequently added, and the solution was heated under an argon atmosphere with magnetic stirring. After the polymerization, the solution was quenched to room temperature, diluted with THF to a known concentration, and analyzed by GPC.

\subsection{Preparation of Poly(methyl methacrylate) Iodide (PMMA-I)}

A $100-\mathrm{mL}$ round-bottom flask containing a mixture of MMA [(20 mL (8 M)], CP-I (80 mM), and BMPI $(40 \mathrm{mM})$ was heated at $60{ }^{\circ} \mathrm{C}$ for $2.75 \mathrm{~h}$ under an argon atmosphere with magnetic stirring. After purification by reprecipitation from cold hexane twice, PMMA-I with $M_{\mathrm{n}}=5100$ and PDI $=1.15$ was isolated. The polymer was then used as a macroinitiator for block copolymerizations (entries 1, 4, 7 , and 8 , in Table 1).

\subsection{Preparation of Poly(butyl acrylate) Iodide (PBA-I)}

A $100-\mathrm{mL}$ round-bottom flask containing a mixture of BA [20 mL (8 M)], CP-I (80 mM), and BNI $(320 \mathrm{mM})$ was heated at $110{ }^{\circ} \mathrm{C}$ for $16 \mathrm{~h}$ under an argon atmosphere with magnetic stirring. After purification by reprecipitation from water/methanol (9:1) twice, PBA-I with $M_{\mathrm{n}}=10,000$ and PDI $=1.33$ was isolated. The polymer was used as a macroinitiator for block copolymerization (entry 10 in Table 1).

\subsection{Surface-Initiated Polymerization}

Silicon wafers (Ferrotec Corp., Tokyo, Japan, chemically/mechanically polished on one side, thickness $525 \mu \mathrm{m}$ ) were cleaned by successive sonication in acetone, water, and 1,2-dichloroethane for $8 \mathrm{~min}$ each and dried in a stream of nitrogen gas followed by evaporation under reduced pressure prior to use. The silicon wafer was immersed in an ethanol solution containing IHE ( $1 \mathrm{wt} \%$ ) and $28 \%$ aqueous $\mathrm{NH}_{3}$ $(5 \mathrm{wt} \%$ ) for $12 \mathrm{~h}$ at room temperature under darkness to immobilize the initiating group and then washed with ethanol. For graft polymerization of MMA, the IHE-immobilized wafer was immersed in a solution containing MMA [3 $\mathrm{mL}(8 \mathrm{M})]$, CP-I $(20 \mathrm{mM})$, NIS $(5 \mathrm{mM})$, and AIBN $(20 \mathrm{mM})$ in a Schlenk flask and subsequently heated at $70{ }^{\circ} \mathrm{C}$ for $4 \mathrm{~h}$ under an argon atmosphere. After polymerization, the solution was diluted with THF to a known concentration and analyzed using GPC. The substrate was copiously rinsed with methanol to remove physisorbed free polymers and impurities. The thickness of the brush layer in the dry state was determined using a rotating compensator spectroscopic ellipsometer (M-2000UTM, J.A. Woolam, Lincoln, NE, USA) equipped with $\mathrm{D}_{2}$ and QTH lamps with a polarizer angle of 45 degrees and an incident angle of 70 degrees. 


\section{Results and Discussion}

\subsection{Diblock Copolymers}

Table 1 summarizes examples of diblock copolymerization, including previously reported [18,27] and new results as indicated.

Table 1 (entries 1-3) shows the block copolymerizations of MMA and GMA. The polymerizations were conducted using three methods. The first method involved polymerization from a purified macroinitiator (polymer-iodide) (entry 1). We prepared the PMMA-I macroinitiator in the bulk RCMP of MMA $(8 \mathrm{M})$ using CP-I $(80 \mathrm{mM})$ as an initiating dormant species and BMPI $(40 \mathrm{mM})$ as a catalyst at $60{ }^{\circ} \mathrm{C}$ for $2.75 \mathrm{~h}$. After purification from hexane, we obtained a purified PMMA-I macroinitiator with $M_{\mathrm{n}}=5500$ and PDI $=1.15$. The iodine elemental analysis indicated that this macroinitiator included a high fraction (95\%) of active polymer possessing iodine at the chain end (with $\pm 5 \%$ experimental error). Such high chain-end fidelity of this macroinitiator can lead to high block efficiency for the subsequent block copolymerizations. Using this macroinitiator, the RCMP of GMA yielded a well-defined diblock copolymers with $M_{\mathrm{n}}=17,000$ and PDI $=1.23$ at $90 \%$ monomer conversion for $6 \mathrm{~h}$ at $60^{\circ} \mathrm{C}$.

The second method involved successive addition of two monomers starting from a purified low-mass dormant species (entry 2). When CP-I was used as a low-mass dormant species, a low-polydispersity diblock copolymer (PDI $=1.34$ ) was obtained. Toluene was used as a solvent to prevent solidification of the first block solution, which facilitated mixing with the second monomer. To overcome the slow polymerization due to dilution, a small amount of an azo compound (V65) was added in the first block. V65 can supply Polymer• and, thus, increase the polymerization rate $R_{\mathrm{p}}$. Azo compounds have often been used to increase $R_{\mathrm{p}}$ in other LRP systems [4-7]. The $R_{\mathrm{p}}$ was sufficiently increased (90\% monomer conversion over $6 \mathrm{~h}$ ) without causing significant broadening of the molecular weight distribution. Because the amount of V65 was approximately 0.15 equivalents compared with CP-I, the obtained block copolymer could include approximately $15 \%$ of dead first-block homopolymer.

The third method involved successive addition of two monomers starting from molecular iodine $\left(\mathrm{I}_{2}\right)$ and an azo compound ( $\mathrm{R}-\mathrm{N}=\mathrm{N}-\mathrm{R})$ (entry 3). An alkyl iodide (R-I) formed in situ in the polymerization serves as the initiating dormant species. This $\mathrm{I}_{2} /$ azo method was originally invented by Lacroix-Desmazes et al. for iodide-mediated LRP [29,30]. This method was also effective for RTCP [17,18] and RCMP [25,27]. A low-polydispersity diblock copolymer (PDI = 1.39) was obtained (entry 3$)$. 
Table 1. Syntheses of diblock copolymers.

\begin{tabular}{|c|c|c|c|c|c|c|c|c|c|c|c|c|c|}
\hline $\begin{array}{c}\text { First block/ } \\
\text { second block }\end{array}$ & Entry & Polymerization & $\begin{array}{c}\text { Monomer } \\
\text { (equiv to [R-I]) } \\
\end{array}$ & R-I & $\operatorname{In}^{a}$ & Cat & $\begin{array}{c}{[\mathrm{M}]_{0} /[\mathrm{R}-\mathrm{I}]_{0} /[\mathrm{In}]_{0} /} \\
{\left[\mathrm{cat}_{\mathbf{0}}{ }^{b}(\mathrm{mM})\right.}\end{array}$ & $T\left({ }^{\circ} \mathbf{C}\right)$ & $t(\mathbf{h})$ & Conv. (\%) & $M_{\mathrm{n}}^{c}\left(M_{\mathrm{n}, \text { theo }}\right)$ & $\mathbf{P D I}^{c}$ & Ref. ${ }^{d}$ \\
\hline \multirow{5}{*}{ MMA/GMA } & 1 & 2nd block & GMA (200 eq) & PMMA-I ${ }^{e}$ & - & BMPI & $8000 / 80 / 80$ & 60 & 6 & 90 & $17,000(17,000)$ & 1.23 & {$[27]$} \\
\hline & \multirow{2}{*}{2} & 1st block & MMA (100 eq) & CP-I & V65 & BMPI & $8000 / 80 / 15 / 80^{f}$ & 60 & 6 & 91 & $8300(9100)$ & 1.13 & - \\
\hline & & 2nd block & GMA (100 eq) & - & - & - & +8000 & 60 & +6 & 200 & $17,000(24,000)$ & 1.34 & - \\
\hline & \multirow{2}{*}{3} & 1st block & MMA (100 eq) & $\mathrm{I}_{2}$ & V70/V65 & BMPI & $8000 / 40 /(60 / 15) / 80^{f}$ & 60 & 6 & 89 & $8200(8900)$ & 1.12 & - \\
\hline & & 2nd block & GMA (100 eq) & - & - & - & +8000 & 60 & +6 & 200 & $17,000(24,000)$ & 1.39 & - \\
\hline \multirow{5}{*}{ MMA/DMAEMA } & 4 & 2nd block & $\begin{array}{l}\text { DMAEMA } \\
(100 \mathrm{eq})\end{array}$ & PMMA-I ${ }^{e}$ & V70 & BMPI & $8000 / 80 / 10 / 10$ & 50 & 2 & 95 & $18,000(19,000)$ & 1.32 & - \\
\hline & \multirow{3}{*}{5} & 1st block & MMA (100 eq) & CP-I & V65 & BMPI & $8000 / 80 / 15 / 80^{f}$ & 60 & 6 & 91 & $8300(9100)$ & 1.25 & - \\
\hline & & 2nd block & $\begin{array}{l}\text { DMAEMA } \\
(100 \mathrm{eq})\end{array}$ & - & V70 & - & $+8000 / 15$ & 50 & +4 & 178 & $21,000(23,000)$ & 1.29 & - \\
\hline & & 1st block & MMA (100 eq) & $\mathrm{I}_{2}$ & V70/V65 & BMPI & $8000 / 40 /(60 / 15) / 80^{f}$ & 60 & 6 & 89 & $8200(8900)$ & 1.12 & - \\
\hline & 6 & 2nd block & $\begin{array}{c}\text { DMAEMA } \\
(100 \mathrm{eq})\end{array}$ & - & V70 & - & $+8000 / 15$ & 50 & +4 & 172 & $21,000(23,000)$ & 1.29 & - \\
\hline MMA/(MMA/MAA) & 7 & 2nd block & $\begin{array}{l}\text { MMA/MAA } \\
(24 / 16 \text { eq) }\end{array}$ & PMMA-I $^{e}$ & V70 & CHD & $8000 / 160 / 80 / 5$ & 40 & 2 & 80 & $6600(5700)$ & 1.31 & {$[18]$} \\
\hline \multirow{3}{*}{ MMA/BA } & 8 & 2nd block & $\mathrm{BA}(100$ eq) & PMMA-I ${ }^{e}$ & - & BNI & $8000 / 80 / 320$ & 110 & 24 & 65 & $15,000(16,000)$ & 1.31 & {$[27]$} \\
\hline & \multirow{2}{*}{9} & 1st block & MMA (100 eq) & $\mathrm{CP}-\mathrm{I}$ & - & BMPI & $8000 / 80 / 80$ & 60 & 5 & 83 & $8400(8300)$ & 1.10 & {$[27]$} \\
\hline & & 2nd block & BA (100 eq) & - & - & $\mathrm{BNI}$ & $8000 / 320$ & 110 & 24 & 155 & $18,000(18,000)$ & 1.32 & {$[27]$} \\
\hline \multirow{3}{*}{ BA/MMA } & 10 & 2nd block & MMA (100 eq) & $\mathrm{PBA}-\mathrm{I}^{e}$ & - & BNI & $8000 / 80 / 320^{g}$ & 110 & 5 & 86 & $16,000(20,000)$ & 1.31 & {$[27]$} \\
\hline & \multirow{2}{*}{11} & 1st block & $\mathrm{BA}(100 \mathrm{eq})$ & $\mathrm{CP}-\mathrm{I}$ & - & BNI & $8000 / 80 / 320$ & 110 & 22 & 82 & $13,000(11,000)$ & 1.28 & {$[27]$} \\
\hline & & 2nd block & MMA (100 eq) & - & - & - & $+8000^{f, g}$ & 110 & 5 & 170 & $27,000(21,000)$ & 1.39 & {$[27]$} \\
\hline
\end{tabular}

${ }^{a} \mathrm{In}=$ conventional azo radical initiator, V65 $=2,2$ '-azobis(2,4-dimethyl valeronitrile), and V70 = 2,2'-azobis(4-methoxy-2,4-dimethyl valeronitrile). ${ }^{b} \mathrm{M}=$ monomer. ${ }^{c}$ Determined by GPC with a multiangle laser light-scattering detector (MALLS) for the first block of entry 11 and PMMA-calibration for others. ${ }^{d}$ Hyphen denotes this work. ${ }^{e}$ PMMA-I $\left(M_{\mathrm{n}}=5100\right.$ and PDI $\left.=1.15\right)$ for entries 1 and 8 , PMMA-I $\left(M_{\mathrm{n}}=2700\right.$ and PDI $\left.=1.15\right)$ for entries 4 and 7 , and PBA-I $\left(M_{\mathrm{n}}=10,000\right.$ and PDI $\left.=1.33\right)$ for entry $10 .{ }^{f}$ Diluted in toluene $(40 \%$ toluene and $60 \%$ MMA for the first block of entries $2,3,5$, and 6$)$ and $(50 \%$ toluene and $50 \%$ MMA for the second block of entry 11$).{ }^{g}$ With the addition of $\mathrm{I}_{2}(4 \mathrm{mM})$. 
In the three cases studied (entries 1-3), the total polymerization time for the first and second blocks was below $12 \mathrm{~h}$. Figure 2 provides the full molecular weight distributions (GPC chromatograms). A large fraction of the first block polymers was extended to block copolymers in all three cases, confirming the high block efficiency due to the high chain-end fidelity demonstrated above.

RTCP and RCMP provide a variety of diblock copolymers, including amphiphilic diblock copolymers consisting of water-insoluble and water-soluble segments. Table 1 shows amphiphilic diblock copolymers with MMA and DMAEMA (water-soluble basic) segments (entries 4-6) and MMA and MMA/MAA (water-soluble acidic) segments (entry 7). The second segment in entry 7 is a random copolymer of MMA $(60 \%)$ and MAA $(40 \%)$, which is water soluble at this monomer composition. Both the basic and acidic segments are accessible as water-soluble segments.

Table 1 (entries 8-11) shows diblock copolymerizations of MMA and BA. We can start with both MMA and BA (as the first block) to obtain well-defined diblock copolymers. In certain LRP systems, the synthetic order of the two blocks is crucial when two different monomer families are used. Thus, the lack of restriction in the synthetic order of the two blocks in the present system is of interest. Figure 3 shows the GPC chromatograms, confirming high block efficiency. These examples demonstrate the high accessibility of RTCP and RCMP to a variety of block copolymers.

Figure 2. GPC chromatograms for MMA/GMA diblock copolymerizations for entries 1-3 in Table 1: (a) entry 1; (b) entry 2; (c) entry 3.

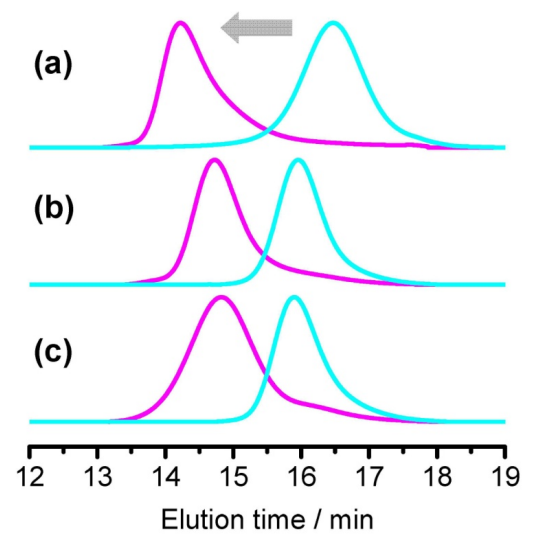

Figure 3. GPC chromatograms for BA/MMA and MMA/BA diblock copolymerizations for entries 8-11 in Table 1: (a) entry 8; (b) entry 9; (c) entry 10; (d) entry 11.

1. From isolated macroinitiator (polymer-1)

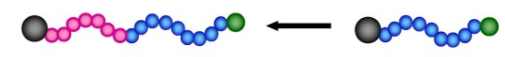

(a)

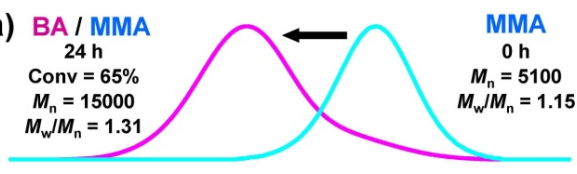

(c) MMA / BA

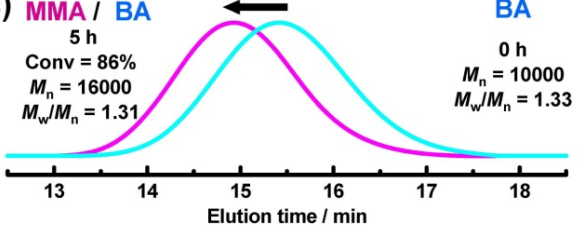

2. Successive addition of two monomers

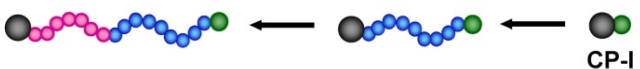

(b) BA / MMA

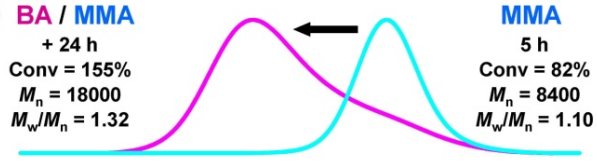

(d) MMA / BA

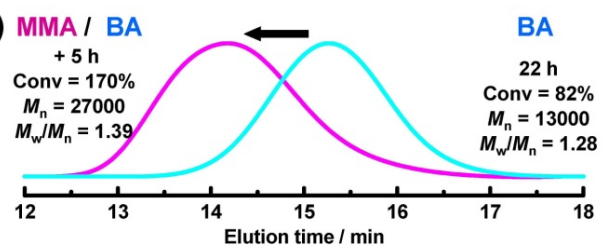




\subsection{Triblock Copolymers}

We attempted to use a difunctional initiator in addition to the above-described monofunctional initiator. We synthesized a difunctional initiator, EMA-II, with two methacrylate-type chain ends (Figure 1). Figure 4 shows the polymerizations of MMA with EMA-II. Low polydispersity polymers of predetermined molecular weight were obtained in both the RTCP with NIS at $40{ }^{\circ} \mathrm{C}$ and the RCMP with BMPI at $80^{\circ} \mathrm{C}$. Figure 5 shows the polymerizations of BA. Again, low polydispersity polymers of predetermined molecular weight were obtained in the RCMP with BNI at $110{ }^{\circ} \mathrm{C}$. These results demonstrate the high initiation efficiency of EMA-II for both MMA and BA polymerizations.

The high initiation efficiency of EMA-II and the aforementioned lack of restricted synthetic order for the two blocks encouraged the preparation of two different types of triblock copolymers of MMA and BA, i.e., BA-MMA-BA and MMA-BA-MMA triblock copolymers [Table 2 (entries 1-3)]. Starting with MMA (as the first block), we obtained a low-polydispersity BA-MMA-BA triblock copolymer $(\mathrm{PDI}=1.31$ ), and starting with BA, we obtained a low-polydispersity MMA-BA-MMA triblock copolymer $(\mathrm{PDI}=1.3-1.4)$. The accessibility of two different types of triblock copolymers is an attractive feature.

The MMA-BA-MMA triblock copolymer is a hard-soft-hard triblock copolymer with a variety of applications including use in elastomers. We also prepared a well-defined MMA-LMA-MMA triblock copolymer [Table 2 (entry 4)] as another hard-soft-hard triblock copolymer. This copolymer is an all-methacrylate copolymer and was easier to prepare with a shorter polymerization time $(12 \mathrm{~h})$ than the MMA-BA-MMA copolymer (21-27 h).

Figure 4. Plots of (a) $\ln \left([\mathrm{M}]_{0} /[\mathrm{M}]\right)$ vs. $t$ and (b) $M_{\mathrm{n}}$ and $M_{\mathrm{w}} / M_{\mathrm{n}} v s$. conversion for the MMA/EMA-II/catalyst systems: $[\mathrm{MMA}]_{0}=8 \mathrm{M}$; [EMA-II $]_{0}=80 \mathrm{mM}$; $[\mathrm{BMPI}]_{0}=80 \mathrm{mM}$ in $50 \%$ toluene at $80{ }^{\circ} \mathrm{C}$ and $[\mathrm{MMA}]_{0}=8 \mathrm{M}$; [EMA-II $]_{0}=40 \mathrm{mM}$; [V70 $]_{0}=10 \mathrm{mM}$; $[\mathrm{NIS}]_{0}=2 \mathrm{mM}$ in $50 \%$ diglyme at $40{ }^{\circ} \mathrm{C}$. The symbols are indicated in the figure.

MMA / EMA-II / catalyst

BMPI $\left(80^{\circ} \mathrm{C}\right)$

- NIS $\left(40^{\circ} \mathrm{C}\right)$

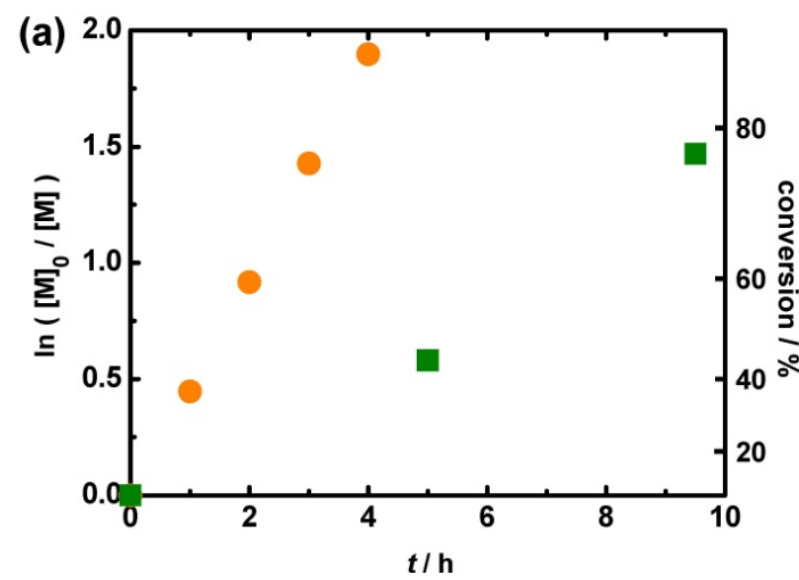

(b)

(b)

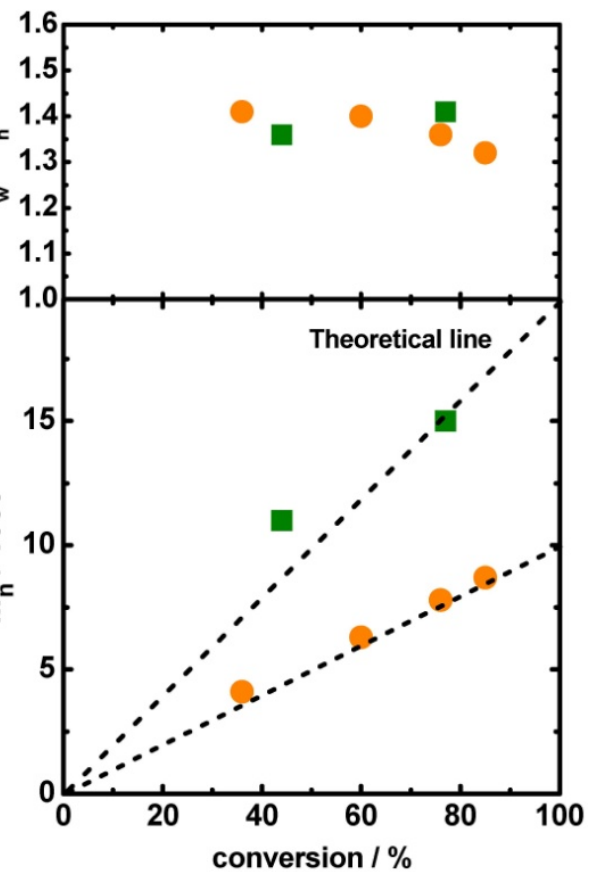


Table 2. Syntheses of triblock copolymers.

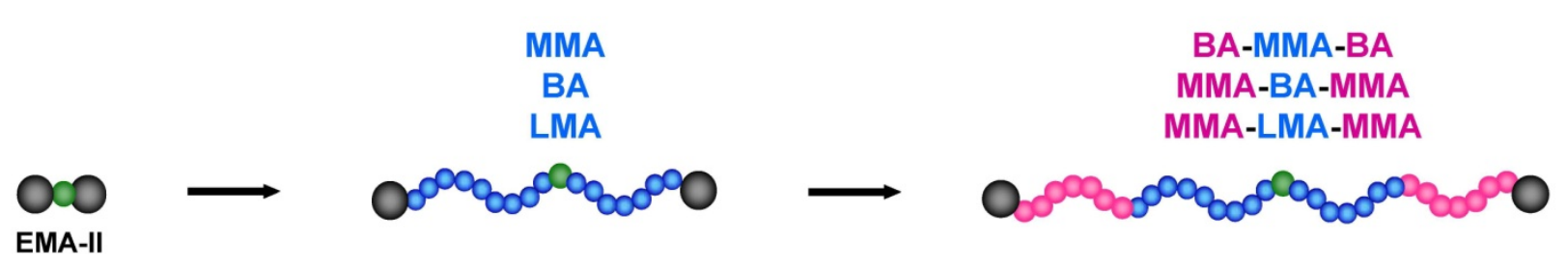

\begin{tabular}{|c|c|c|c|c|c|c|c|c|c|c|c|c|}
\hline ABA block & Entry & Polymerization & $\begin{array}{c}\text { Monomer } \\
\text { (equiv to [R-I]) }\end{array}$ & R-I & $\operatorname{In}^{a}$ & Cat & $\begin{array}{c}{[\mathrm{M}]_{0} /[\mathrm{R}-\mathrm{I}]_{0} /[\mathrm{In}]_{0} /} \\
{\left[\mathrm{cat}_{0}{ }_{0}{ }^{b}(\mathrm{mM})\right.}\end{array}$ & $T\left({ }^{\circ} \mathbf{C}\right)$ & $t(\mathbf{h})$ & Conv. (\%) & $M_{\mathrm{n}}^{c}\left(M_{\mathrm{n}, \text { theo }}\right)$ & $\mathbf{P D I}^{c}$ \\
\hline \multirow{2}{*}{ BA/MMA/BA } & \multirow{2}{*}{1} & 1st block & MMA (100 eq) & EMA-II & - & BMPI & $8000 / 80 / 80^{d}$ & 80 & 6 & 85 & $8800(8500)$ & 1.32 \\
\hline & & 2nd block & BA (100 eq) & - & - & $\mathrm{BNI}$ & $+8000 / 320$ & 110 & +24 & 154 & $17,000(18,000)$ & 1.31 \\
\hline \multirow{4}{*}{ MMA/BA/MMA } & \multirow{2}{*}{2} & 1st block & BA (100 eq) & EMA-II & - & $\mathrm{BNI}$ & $8000 / 80 / 320$ & 110 & 23 & 89 & $13,000(11,000)$ & 1.21 \\
\hline & & 2nd block & MMA (100 eq) & - & - & - & $+8000^{d, e}$ & 110 & +5 & 186 & $23,000(21,000)$ & 1.33 \\
\hline & \multirow{2}{*}{3} & 1st block & BA (100 eq) & EMA-II & - & $\mathrm{BNI} / \mathrm{DABCO}$ & $8000 / 80 /(320 / 15)$ & 110 & 16 & 87 & $14,000(11,000)$ & 1.37 \\
\hline & & 2nd block & MMA (100 eq) & - & - & - & $+8000^{d}$ & 110 & +5 & 176 & $25,000(20,000)$ & 1.39 \\
\hline \multirow{2}{*}{ MMA/LMA/MMA } & \multirow[b]{2}{*}{4} & 1st block & LMA (100 eq) & EMA-II & V65 & BMPI & $8000 / 80 / 15 / 80^{d}$ & 60 & 6 & 84 & $17,000(21,000)$ & 1.31 \\
\hline & & 2nd block & MMA (100 eq) & - & V65 & & $8000 / 10$ & 60 & +6 & 162 & $24,000(29,000)$ & 1.33 \\
\hline
\end{tabular}

${ }^{a}$ In = conventional azo radical initiator, and V65 $=2,2$-azobis(2,4-dimethyl valeronitrile). ${ }^{b} \mathrm{M}=$ monomer. ${ }^{c}$ Determined by GPC with a multiangle laser light-scattering detector (MALLS) for the first block of entries 2-4 and PMMA-calibration for others. ${ }^{d}$ Diluted in toluene (50\% toluene and 50\% MMA for the first block of entries 1 and the second block of entries 2 and 3 and $40 \% \mathrm{~N}, \mathrm{~N}$-dimethyl 2-methoxyethylamide and $60 \%$ LMA for the first block of entry 4$).{ }^{e}$ With the addition of $\mathrm{I}_{2}(4 \mathrm{mM})$. 
Figure 5. Plots of (a) $\ln \left([\mathrm{M}]_{0} /[\mathrm{M}]\right)$ vs. $t$ and (b) $M_{\mathrm{n}}$ and $M_{\mathrm{w}} / M_{\mathrm{n}} v s$. conversion for the $\mathrm{BA} / \mathrm{EMA}-\mathrm{II} / \mathrm{BNI}$ systems in bulk $\left(110{ }^{\circ} \mathrm{C}\right):[\mathrm{BA}]_{0}=8 \mathrm{M}$; [EMA-II $]_{0}=80$ or $40 \mathrm{mM}$; $[\mathrm{BNI}]_{0}=320 \mathrm{mM}$. The symbols are indicated in the figure.

BA / EMA-II / BNI / $110^{\circ} \mathrm{C}$

EMA-II $(80 \mathrm{mM})$

EMA-II (40 mM)

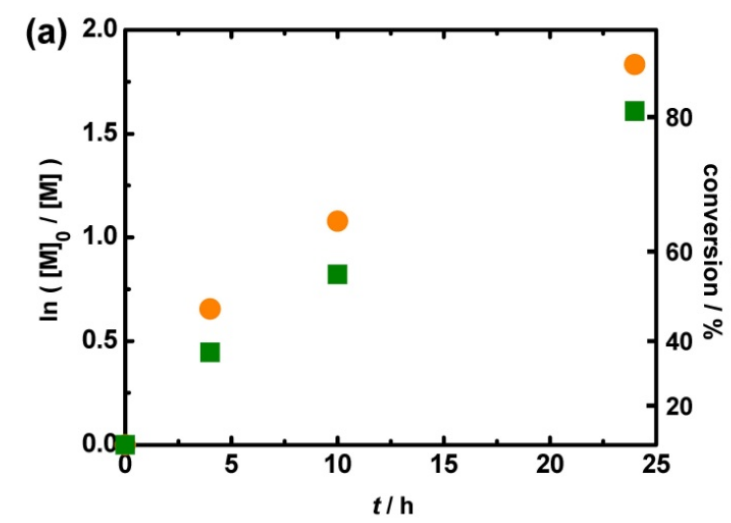

(b)

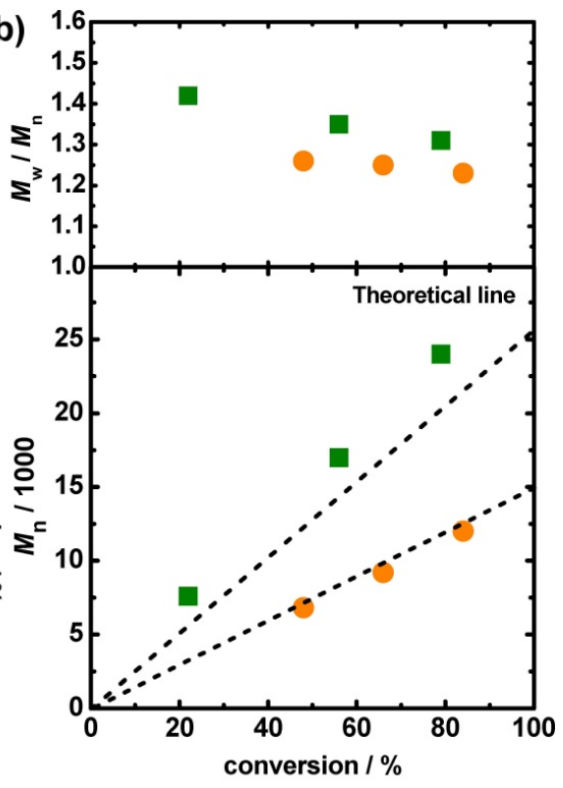

\subsection{Three-Arm Star Polymer}

In addition to linear polymers, we also prepared a 3-arm star polymer from a trifunctional initiator. We synthesized EMA-III as a trifunctional initiator (Figure 1). Figure 6 shows the RCMP of MMA from EMA-III with BNI at $60{ }^{\circ} \mathrm{C}$. The molecular weights were determined by GPC-MALLS. The $M_{\mathrm{n}}$ was in good agreement with the theoretical value and PDI was about 1.2 at a later stage of polymerization. A 3-arm star polymer with $M_{\mathrm{n}}=34,000$ and PDI $=1.22$ was obtained as an example.

Figure 6. Plots of (a) $\ln \left([\mathrm{M}]_{0} /[\mathrm{M}]\right)$ vs. $t$ and (b) $M_{\mathrm{n}}$ and $M_{\mathrm{w}} / M_{\mathrm{n}} v s$. conversion for the MMA/EMA-II/BNI system $\left(60{ }^{\circ} \mathrm{C}\right):[\mathrm{MMA}]_{0}=8 \mathrm{M} ;[\mathrm{EMA}-\mathrm{III}]_{0}=20 \mathrm{mM} ;[\mathrm{BNI}]_{0}=80 \mathrm{mM}$ in $25 \%$ toluene.

MMA / EMA-III / BNI / $60^{\circ} \mathrm{C}$

(b)

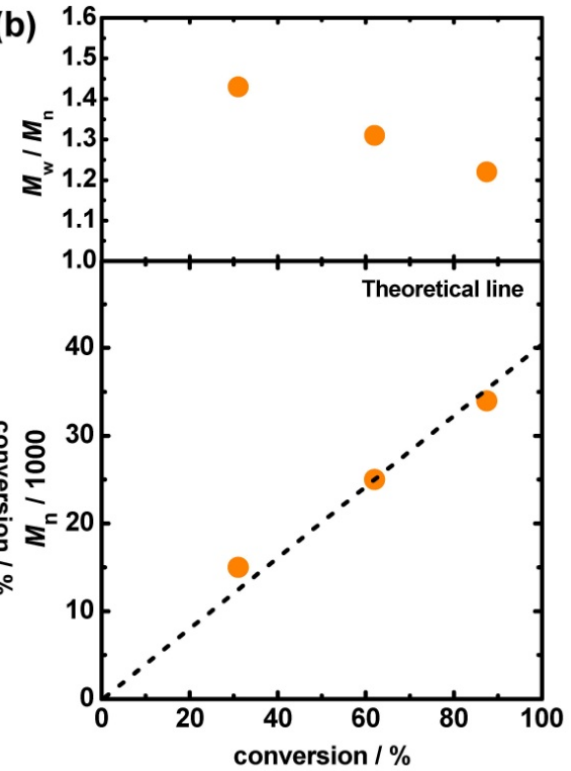

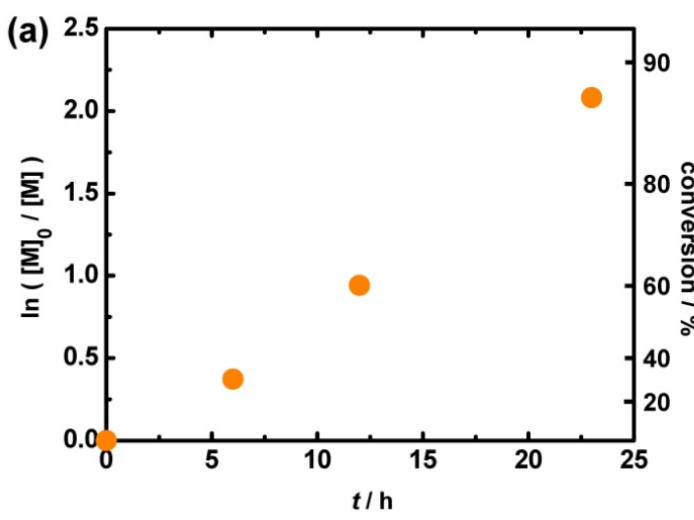

" 


\subsection{Surface-Initiated Polymerization-Concentrated Polymer Brush}

A surface of material plays a crucial role in many important properties such as mechanical, thermodynamic, and chemical properties; thus, surface modification is an important issue [31-33]. Surface-initiated graft polymerization is among the most effective surface modification methods. Fukuda and Tsujii et al. [31,34] were the first to use LRP in graft polymerization to obtain a polymer brush with a surface density that was one order of magnitude higher than those of conventional brushes. The surface occupancy reached $40 \%$. This so-called concentrated polymer brush takes a highly extended conformation, with extension up to $80 \%$ of all-trans conformation length in good solvents [31]. Such an extended conformation affords many new properties not attainable by conventional semi-dilute and dilute brushes, such as high elasticity, ultra-low friction, and excellent repellency of proteins and cells. Therefore, concentrated brushes may have useful applications [31-33].

Given these results, surface-initiated RTCP was studied. We synthesized a surface-immobilizing initiator IHE (Figure 1) consisting of an alkyl iodide (initiating) moiety and a triethoxysilyl (TEOS) group. IHE was synthesized from BHE (the previously reported corresponding bromide) [28] via a halogen exchange reaction with NaI. IHE was fixed on a silicon wafer through the TEOS group. The IHE-immobilized silicon wafer was immersed in a mixture of MMA, a non-immobilized free initiator CP-I, a catalyst NIS, and a radical source AIBN, and heated at $70{ }^{\circ} \mathrm{C}$ for $4 \mathrm{~h}$ for polymerization (Figure 7). The free initiator CP-I was added because its addition can improve control over $M_{\mathrm{n}}$ and PDI of the immobilized graft polymer [31-33]. The $M_{n}$ and PDI of the free polymers generated from free initiators, which are usually in good agreement with those of the immobilized graft polymers [31-33], were 15,000 and 1.31, respectively. The thickness of the graft polymer was measured to be $10.5 \mathrm{~nm}$ using ellipsometry. Assuming the same $M_{\mathrm{n}}$ for the graft and free polymers, the surface density of the graft polymer was calculated to be 0.51 chains $/ \mathrm{nm}^{2}$. This density is high and located in a concentrated polymer brush region [31], indicating the successful controlled synthesis of a concentrated polymer brush.

Figure 7. Surface-initiated RTCP of MMA. The experimental conditions are indicated in the figure.

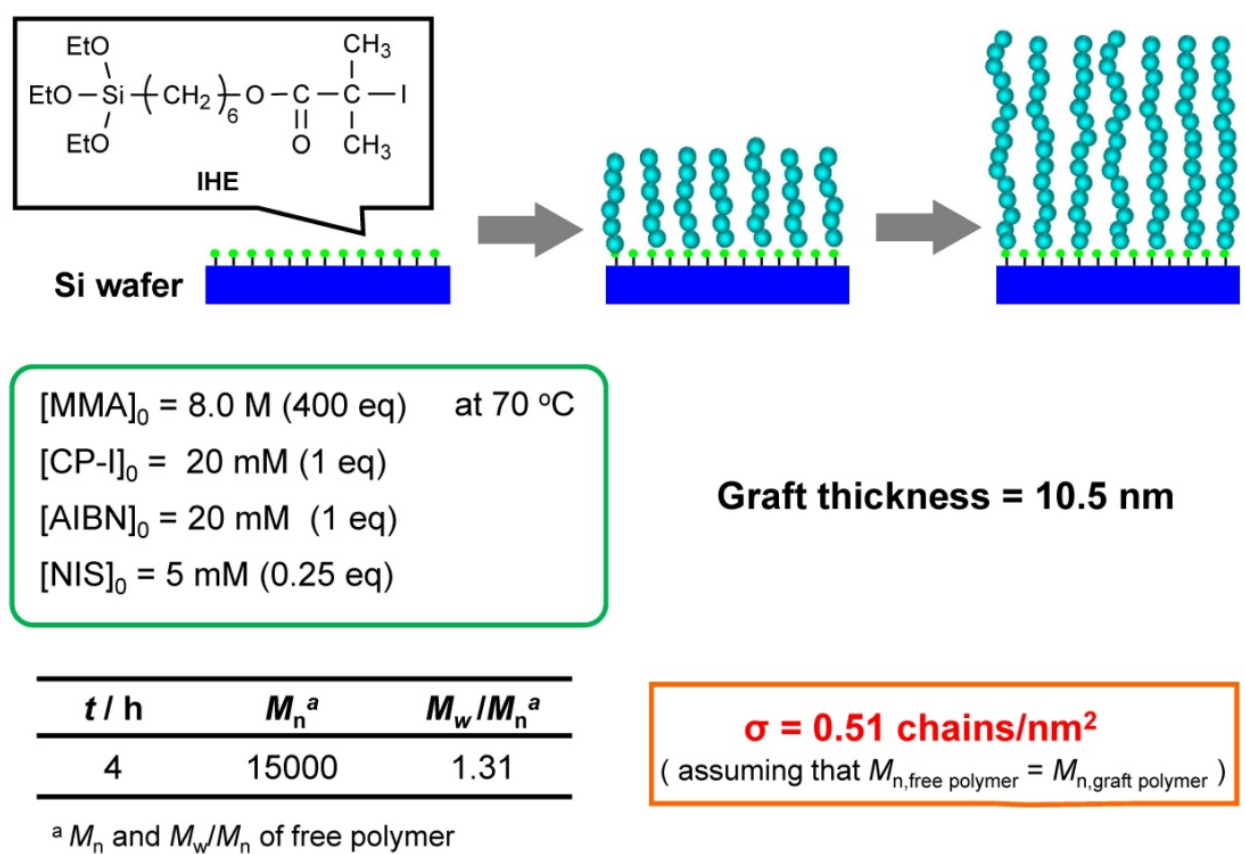


Another example of the graft polymerization is depicted in Figure 8, in which IHE was fixed on the surface in a patterned manner. For demonstration purposes, we carried out an RTCP of BzMA, using a non-toxic catalyst vitamin $\mathrm{E}$, without a priori purge of inert gas for the short time of $5 \mathrm{~min}$ at $85{ }^{\circ} \mathrm{C}$. After the polymerization, the polymer brushes were observed as black square spots (Figure 8), demonstrating patterning and a robust and quick polymer brush synthesis.

Figure 8. Surface-initiated RTCP of BzMA: $[\mathrm{BzMA}]_{0}=8.0 \mathrm{M} ;[\mathrm{CP}-\mathrm{I}]_{0}=60 \mathrm{mM}$; $[\text { di(4-t-butylcyclohexyl) peroxydicarbonate }]_{0}=60 \mathrm{mM} ;[\text { Vitamin } \mathrm{E}]_{0}=10 \mathrm{mM}$; IHE-immobilized wafer $\left(85^{\circ} \mathrm{C}\right)$; in $25 \%$ toluene for $5 \mathrm{~min}$. The conversion was $80 \%$. The $M_{\mathrm{n}}$ and PDI of the free polymer were 13,000 and 1.45 , respectively. The surface density was estimated to be 0.48 chains $/ \mathrm{nm}^{2}$. The figure in the right-bottom part shows a microscope image of polymer brush patterned on surface.
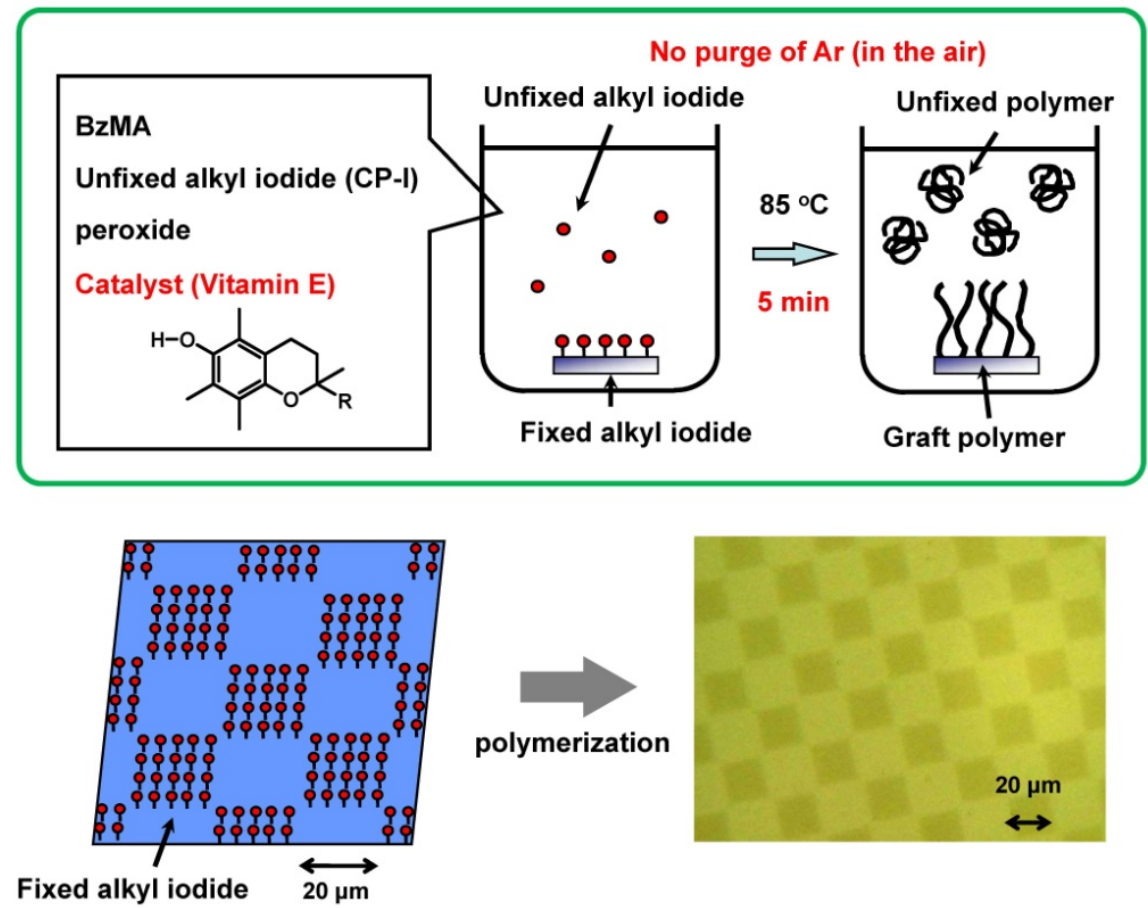

\section{Conclusions}

Diblock copolymers were synthesized using a purified macroinitiator and the successive addition of two monomers. Well-defined triblock and star polymers and concentrated polymer brushes on solid surfaces were synthesized from difunctional, trifunctional, and surface-immobilized initiators. We prepared two different types of triblock copolymers using MMA and BA: MMA-BA-MMA and BA-MMA-BA copolymers. Access to a variety of macromolecular architectural designs may be beneficial to a variety of applications.

\section{Acknowledgments}

This work was partially supported by Grants-in-Aid for Scientific Research from the Japan Society of the Promotion of Science (JSPS) and the Japan Science and Technology Agency (JST). 


\section{Conflicts of Interest}

The authors declare no conflict of interest.

\section{References}

1. Tsarevsky, N.V.; Sumerlin, B.S. Fundamentals of Controlled/Living Radical Polymerization; Royal Society of Chemistry: London, UK, 2013.

2. Matyjaszewski, K.; Möller, M. Polymer Science: A Comprehensive Reference; Elsevier: Amsterdam, The Netherlands, 2012.

3. Moad, G.; Solomon, D.H. The Chemistry of Radical Polymerization; Elsevier: Amsterdam, The Netherlands, 2006.

4. Fukuda, T. Fundamental kinetic aspects of living radical polymerization and the use of gel permeation chromatography to shed light on them. J. Polym. Sci. Part A Polym. Chem. 2004, 42, 4743-4755.

5. Fischer, H. The persistent radical effect: A principle for selective radical reactions and living radical polymerizations. Chem. Rev. 2001, 101, 3581-3618.

6. Goto, A.; Fukuda, T. Kinetics of living radical polymerization. Prog. Polym. Sci. 2004, 29, 329-385.

7. Fukuda, T.; Goto, A. Controlled and Living Radical Polymerization-Principles and Fundamentals. In Polymer Science: A Comprehensive Reference; Matyjaszewski, K., Möller, M., Eds.; Elsevier: Amsterdam, The Netherlands, 2012; pp. 120-157.

8. Sciannamea, V.; Jérôme, R.; Detrembleur, C. In-situ nitroxide-mediated radical polymerization (NMP) processes: Their understanding and optimization. Chem. Rev. 2008, 108, 1104-1126.

9. Moad, G.; Rizzardo, E.; Thang, S.H. Living radical polymerization by the RAFT process-A second update. Aust. J. Chem. 2009, 62, 1402-1472.

10. Keddie, D.J.; Moad, G.; Rizzado, E.; Thang, S.H. RAFT agent design and synthesis. Macromolecules 2012, 45, 5321-5342.

11. David, G.; Boyer, C.; Tonnar, J.; Ameduri, B.; Lacroix-Desmazes, P.; Boutevin, B. Use of iodocompounds in radical polymerization. Chem. Rev. 2006, 106, 3936-3962.

12. Yamago, S. Precision polymer synthesis by degenerative transfer controlled/living radical polymerization using organotellurium, organostibine, and organobismuthine chain-transfer agents. Chem. Rev. 2009, 109, 5051-5068.

13. Ouchi, M.; Terashima, T.; Sawamoto, M. Transition metal-catalyzed living radical polymerization: Toward perfection in catalysis and precision polymer synthesis. Chem. Rev. 2009, 109, 4963-5050.

14. Lena, F.; Matyjaszewski, K. Transition metal catalysts for controlled radical polymerization. Prog. Polym. Sci. 2010, 35, 959-1021.

15. Matyjaszewski, K. Atom transfer radical polymerization (ATRP): Current status and future perspectives. Macromolecules 2012, 45, 4015-4039.

16. Goto, A.; Zushi, H.; Hirai, N.; Wakada, T.; Tsujii, Y.; Fukuda, T. Living radical polymerizations with germanium, tin, and phosphorus catalysts-Reversible chain transfer catalyzed polymerizations (RTCPs). J. Am. Chem. Soc. 2007, 129, 13347-13354. 
17. Goto, A.; Hirai, N.; Wakada, T.; Nagasawa, K.; Tsujii, Y.; Fukuda, T. Living radical polymerization with nitrogen Catalyst: Reversible chain transfer catalyzed polymerization with $\mathrm{N}$-iodosuccinimide. Macromolecules 2008, 41, 6261-6264.

18. Goto, A.; Hirai, N.; Nagasawa, K.; Tsujii, Y.; Fukuda, T.; Kaji, H. Phenols and carbon compounds as efficient organic catalysts for reversible chain transfer catalyzed living radical polymerization (RTCP). Macromolecules 2010, 43, 7971-7978.

19. Vana, P.; Goto, A. Kinetic simulations of reversible chain transfer catalyzed polymerization (RTCP): Guidelines to optimum molecular weight control. Macromol. Theory Simul. 2010, 19, 24-35.

20. Yorizane, M.; Nagasuga, T.; Kitayama, Y.; Tanaka, A.; Minami, H.; Goto, A.; Fukuda, T.; Okubo, M. Reversible chain transfer catalyzed polymerization (RTCP) of methyl methacrylate with nitrogen catalyst in an aqueous microsuspension system. Macromolecules 2010, 43, 8703-8705.

21. Kuroda, T.; Tanaka, A.; Taniyama, T.; Minami, H.; Goto, A.; Fukuda, T.; Okubo, M. Iodine transfer dispersion polymerization (dispersion ITP) with $\mathrm{CHI}_{3}$ and reversible chain transfer catalyzed dispersion polymerization (dispersion RTCP) with $\mathrm{GeI}_{4}$ of styrene in supercritical carbon dioxide. Polymer 2012, 53, 1212-1218.

22. Goto, A.; Tsujii, Y.; Fukuda, T. Reversible chain transfer catalyzed polymerization (RTCP): A new class of living radical polymerization. Polymer 2008, 49, 5177-5185.

23. Goto, A.; Tsujii, Y.; Kaji, H. Living Radical Polymerizations with Organic Catalysts. In Fundamentals of Controlled/Living Radical Polymerization; Tsarevsky, N.V., Sumerlin, B.S., Eds.; Royal Society of Chemistry: London, UK, 2013; pp. 250-286.

24. Goto, A.; Suzuki, T.; Ohfuji, H.; Tanishima, M.; Fukuda, T.; Tsujii, Y.; Kaji, H. Reversible complexation mediated living radical polymerization (RCMP) using organic catalysts. Macromolecules 2011, 44, 8709-8715.

25. Goto, A.; Tsujii, Y.; Kaji, H. Reversible complexation mediated polymerization (RCMP) of methyl methacrylate. ACS Symp. Ser. 2012, 1100, 305-315.

26. Ohtsuki, A.; Goto, A.; Kaji, H. Visible-Light-Induced reversible complexation mediated living radical polymerization of methacrylates with organic catalysts. Macromolecules 2013, 46, 96-102.

27. Goto, A.; Ohtsuki A.; Ohfuji, H.; Tanishima, M.; Kaji, H. Reversible generation of a carbon-centered radical from alkyl iodide using organic salts and their application as organic catalysts in living radical polymerization. J. Am. Chem. Soc. 2013, 135, 11131-11139.

28. Ohno, K.; Morinaga, T.; Koh, K.; Tsujii, Y.; Fukuda, T. Synthesis of monodisperse silica particles coated with well-defined, high-density polymer brushes by surface-initiated atom transfer radical polymerization. Macromolecules 2005, 38, 2137-2142.

29. Lacroix-Desmazes, P.; Severac, R.; Boutevin, B. Reverse iodine transfer polymerization of methyl acrylate and n-butyl acrylate. Macromolecules 2005, 38, 6299-6309.

30. Tonnar, P.; Lacroix-Desmazes, P. Use of sodium iodide as the precursor to the control agent in ab initio emulsion polymerization. Angew. Chem. Int. Ed. 2008, 47, 1294-1297.

31. Tsujii, Y.; Ohno, K.; Yamamoto, S.; Goto, A.; Fukuda, T. Structure and properties of high-density polymer brushes prepared by surface-initiated living radical polymerization. Adv. Polym. Sci. 2006, 197, 1-45.

32. Edmondson, S.; Osborne, V.L.; Huck, W.T.S. Polymer brushes via surface-initiated polymerizations. Chem. Soc. Rev. 2004, 33, 14-22. 
33. Barbey, R.; Lavanant, L.; Paripovic, D.; Schuwer, N. Sugnaux, C.; Tugulu, S.; Klok, H. Polymer brushes via surface-initiated controlled radical polymerization: Synthesis, characterization, properties, and applications. Chem. Rev. 2009, 109, 5437-5527.

34. Ejaz, M.; Yamamoto, S.; Ohno, K.; Tsujii, Y.; Fukuda, T. Controlled graft polymerization of methyl methacrylate on silicon substrate by the combined use of the langmuir-blodgett and atom transfer radical polymerization techniques. Macromolecules 1998, 31, 5934-5936.

(C) 2014 by the authors; licensee MDPI, Basel, Switzerland. This article is an open access article distributed under the terms and conditions of the Creative Commons Attribution license (http://creativecommons.org/licenses/by/3.0/). 